\title{
Sciatic nerve injury following gluteal intramuscular injection
}

\author{
Mohammed M. Fathi Alsheikh \\ Department of Medicine, College of Medicine, University of Mosul.
}

(Ann. Coll. Med. Mosul 2011; 37 (1 \& 2): 87-92).

Received: $4^{\text {th }}$ Jan 2011; Accepted: $5^{\text {th }}$ Jun 2011.

\begin{abstract}
Objective: To study the type of injected agents, clinical features and outcome of conservative treatment of patients with sciatic nerve injury following gluteal intramuscular injection.

Methods: A prospective study of patients with sciatic nerve injury following gluteal intramuscular injection from private neurological clinic and neurophysiology unit in Ibn Sena Teaching Hospital in Mosul between January 2008 and July 2010.

Results: The total number of the patients was 36 . Male patients were 19 and females were 17 . There were 28 patients under age of 5 years. Thirty four patients sustained their nerve injury by nurses, and antibiotics were the offending agents in $91.33 \%$ of patients. Foot drop is the commonest presenting clinical feature. Complete recovery was reported in $29.6 \%$ of the patients, partial recovery in $44.5 \%$ and no measurable clinical improvement in $25.5 \%$ of them.
\end{abstract}

Conclusion: Children are at higher risk of injury. The injection should be prescribed only when mandatory and administered by a well qualified and competent personnel.

Keywords: Intramuscular injection, sciatic nerve, sciatic nerve injury.

الهُف: دراسة أنواع الحقن و العلامات السريرية ونتائج العلاج التحفظي للمرضى الذين يعانون من إصابة العصب الإنسي

نتيجة الحقن في عضلة الإلية.

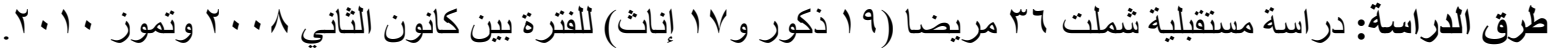

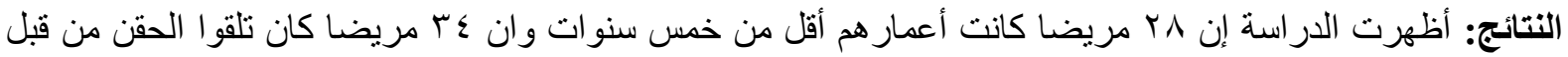

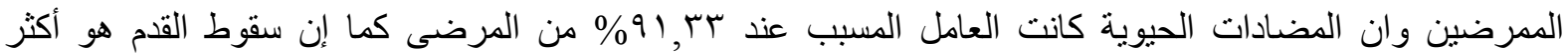

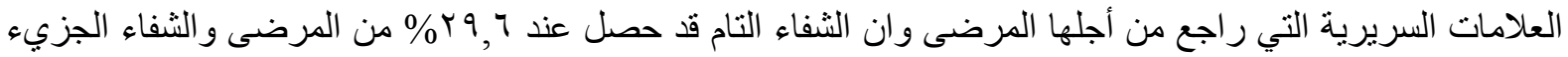

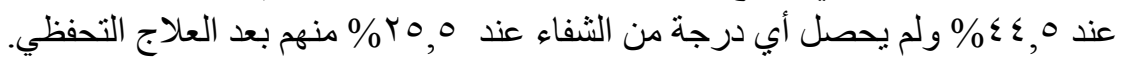
الاستتتاجات: الأطفال هم الأكثر عرضة للإصابة. تنصح هذه الدراسة بعدم استخدام الحقن بالعضلة إلا في الحالات

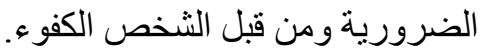

$S$ ciatic neuropathy is the second commonest mononeuropathy in the lower limbs after common peroneal nerve injury. The vulnerability of the nerve to damage is attributed to its long anatomic course from lumbosacral plexus, through the sciatic notch down to its bifurcation just above the popliteal fossa ${ }^{(1,2)}$. Sciatic nerve injury following intragluteal injection is the second most common cause of sciatic nerve injury after hip arthroplasty (2). Apart from the risk of transmission of blood-borne diseases, improper injection technique can cause peripheral nerves damage; most commonly of 
the radial nerve in the upper limbs and sciatic nerve in the lower limbs especially in paediatric populations ${ }^{(3,4,5)}$.

Damage to the sciatic nerve by injection has been reported from several parts of the world; these injuries are related mainly to a faulty injection technique and lack of trained manpower capable of administering paranteral drugs in the developing countries ${ }^{(1,6,7)}$. Injection injury account for $50 \%$ of sciatic nerve injuries in one large series reported from the USA ${ }^{(4)}$.

The degree of nerve fiber injury depends on the site of injection and upon the specific agent injected. The pathological alteration in the nerve is evident as early as 30 minutes following injection injury in the form of widespread axonal and myelin degeneration $(7,8)$

The mechanism of injury includes direct needle trauma, secondary constriction by scar and direct nerve fiber damage to both axon and Shwan cell, with breakdown in the bloodnerve barrier by neurotoxic chemicals in the injected agent ${ }^{(9)}$. A review of literature on relevant injection procedure found that injury to sciatic nerve is associated with the use of dorsogluteal site for injection because the sciatic nerve commonly courses this site ${ }^{(10)}$. The World Health Organization (WHO) estimates that of the 12 billion injections administered worldwide annually, 50\% are unsafe and $75 \%$ are unnecessary ${ }^{(11)}$.

This study was conducted to analyze the type of injected agents, clinical features and outcome of a conservative treatment of patients with sciatic nerve injury following gluteal intramuscular injection.

\section{Materials and methods}

This was a prospective study for the period from January 2008 to July 2010.

We were able to identify a total of 36 patients from private neurological clinic, and neurophysiology unit in Ibn Sena Teaching Hospital in Mosul that satisfied our inclusion criteria (i.e. neurological symptoms and / or signs in lower limb following an intragluteal injection).

All patients had history of recent gluteal intramuscular injection and they did not have any weakness in the limbs or associated sensory disturbances before the injection. They had received complete polio immunization together with stool examination to exclude patients with poliomyelitis.

The motor symptoms and signs were graded using the Medical Research Councel (MRC) grading score (0-5) for knee flexion, foot dorsiflexion and planter flexion muscles ${ }^{(11,12)}$. But this is was not possible in three patients because they had only sensory symptoms and signs.

The relative involvement of the common peroneal and posterior tibial nerve were determined by comparing the power grade in the dorsiflexion and planter flexion of the foot at the time of the first presentation.

The nerve conduction study was done in the lower limb nerves: the common peroneal and posterior tibial. The recording was done over the extensor digitorum brevis and the abductor halloucis longus muscles, the sensory nerve conduction study involves the sural and superficial peroneal nerves.

A total of 36 patients were followed up every 2 months during the study with clinical evaluation to assess the degree of improvement by using MRC clinical grading of power and they were divided in 3 groups:

1- Complete recovery: when MRC clinical grade of power is 5 on the last follow up visit.

2- Partial recovery: when the power recovered by $>1$ grade from the baseline on the last follow up visit.

3- No recovery when there was no measurable improvement from the baseline in the last follow up visit ${ }^{(12)}$.

\section{Results}

Of the 36 patients fulfilling the inclusion criteria, 19 patients $(52.77 \%)$ were males and 17 patients $(27.33 \%)$ females, male:female ratio $1.12: 1$.

There were 28 patients $(77.77 \%)$ under the age of five years.(Fig.1)

The majority of these patients 34 (94.45\%) has sustained their nerve injury by nurses and 2 patients (5.55\%) by doctors. 
Unfortunately the exact site of the gluteal injection could not be identified in all the patients.

The indication for administration of the gluteal intramuscular injection is shown in Table(1); by far the most common condition for which intramuscular injection of the drug was given was upper respiratory tract infections $69.44 \%$.

Antibiotics injections (cefotaxime, ampicillin, procaine penicillin) were the offending agent in 33 patients $(91.33 \%)$, while 3 patients $(8.33 \%)$ had diclofenac sodium and acetaminophen injections. The sex distribution according to the side affected was show in table (2).

Twenty three patients $(63.88 \%)$ were affected on the left side while 13 patients $(36.12 \%)$ had the injury on the right side and the left side was more commonly affected in both male and female patients.

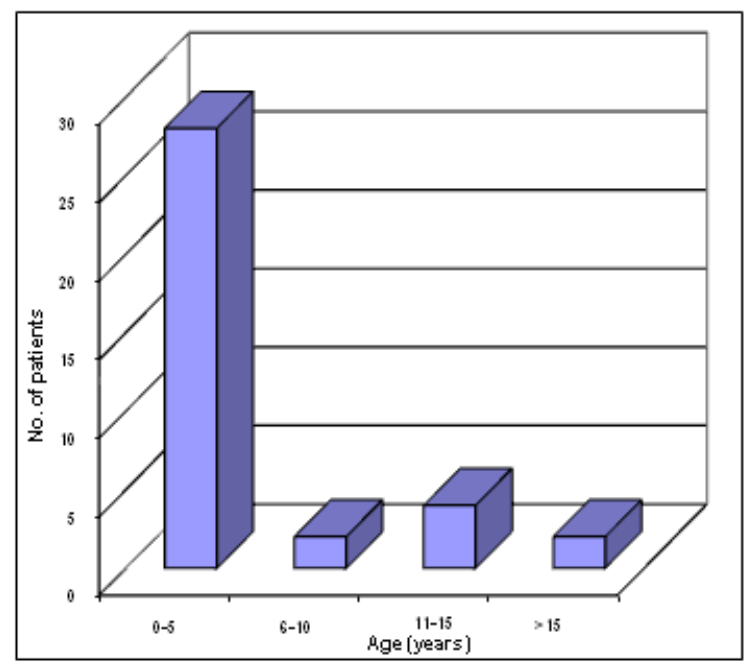

Figure (1): Age distribution.

Table (1): Indications for giving injections and the number and percentage of patients.

\begin{tabular}{|l|c|c|}
\hline \multicolumn{1}{|c|}{$\begin{array}{c}\text { Indication for } \\
\text { injection }\end{array}$} & $\begin{array}{c}\text { Number } \\
\text { affected }\end{array}$ & \% of total \\
\hline $\begin{array}{l}\text { Upper respiratory } \\
\text { tract infections }\end{array}$ & 25 & 69.44 \\
\hline Diarrheal diseases & 5 & 13.88 \\
\hline Back pain & 3 & 8.33 \\
\hline $\begin{array}{l}\text { Urinary tract } \\
\text { infections }\end{array}$ & 2 & 5.55 \\
\hline Otitis media & 1 & 2.77 \\
\hline
\end{tabular}

The onset of the symptoms was immediate in 34 patients (94.44\%) and delayed for few hours in 2 patients $(5.55 \%)$.

Table (3) showed the chief complaint at presentation. There was post injection foot drop in 19 patients $(52.77 \%)$, weakness of the leg and foot in 11 patients (30.55\%), pain and numbness in 3 patients (8.33\%), equinovarus deformity in 2 patients (5.55\%) and fibrotic scar in gluteal region in 1 patient (2.77\%).

All the patients had undergone an initial electrophysiological study at mean of 3 months ( 3 weeks to 15 months) from the onset of the symptoms. The results of the electrophysiological study revealed that 3 patients $(8.33 \%)$ had decreased sensory nerve action potential (SNAP) in the sural nerve without any motor conduction abnormalities (these in patients presented with sensory symptoms and signs only). Twelve patients (33.33\%) had isolated involvement of the common peroneal nerve, seven patients (19.44\%) had involvement of the posterior tibial nerve, and 14 patients (38.88\%) had involvement of both common peroneal and posterior tibial nerves equally.

Table (2): Sex distribution of the limbs affected.

\begin{tabular}{|c|c|c|}
\hline Sex & $\begin{array}{c}\text { Number of } \\
\text { patient }\end{array}$ & \% Total \\
\hline Male & 9 & 25 \\
Right & 10 & 27.77 \\
Left & 4 & 11.11 \\
\hline $\begin{array}{c}\text { Female } \\
\text { Right } \\
\text { Left }\end{array}$ & 13 & 36.11 \\
\hline Total & 36 & \\
\hline
\end{tabular}

Table (3): Symptoms at presentation.

\begin{tabular}{|l|c|c|}
\hline \multicolumn{1}{|c|}{ Symptoms } & $\begin{array}{c}\text { Number of } \\
\text { patients }\end{array}$ & \% Total \\
\hline Foot drop & 19 & 52.77 \\
\hline $\begin{array}{l}\text { Leg and foot } \\
\text { weakness }\end{array}$ & 11 & 30.55 \\
\hline Pain and numbness & 3 & 8.33 \\
\hline $\begin{array}{l}\text { Equinovarus } \\
\text { deformity }\end{array}$ & 2 & 5.55 \\
\hline Fibrotic scar & 1 & 2.77 \\
\hline Total & 36 & \\
\hline
\end{tabular}


Thirty two patients $(88.88 \%)$ were treated conservatively by vitamins, physiotherapy, ankle brace and pain medication (for the patients with pain and numbness).

Four patients (12.9\%) were treated by tendon transfer because of their late consultation (more than 15 months) and yielded good results.

Five patients out of the 32 patients who were treated conservatively discontinued their follow up, the reminder 27 patients were followed up 8-18 months (mean followed up period 10 months) in the prospective phase of the study with clinical evaluation to assess the degree of improvement.

Eight patients (29.6\%) completely recovered, 12 patients $(44.5 \%)$ showed partial recovery and 7 patients $(25.5 \%)$ had no clinically measurable improvement from the baseline.

Three patients of those with complete recovery had only sensory signs and symptoms at presentation.

During follow up, 3 patients (9.6\%) developed atrophic changes in forms of wasting and ulceration in the leg and toes.

\section{Discussion}

Post injection sciatic nerve injury can occur in both adults and children. In this study the children are affected more than adult and $77.77 \%$ of the patients were under the age of 5 years. In other two studies $77.5 \%$ and $86.36 \%$ of the patients respectively were under this age ${ }^{(13,14)}$. Since children have various thickness of the subcutaneous tissue and depth of gluteus musculature, the chance of involvement of sciatic nerve is more than in adults $^{(14,15)}$ and gluteal intramuscular administration of drugs is presently a common practice among the paediatric age groups. Some health workers have strong preferences for injection and infusions even when oral and other alternative routes are equally good and safe ${ }^{(13)}$.

Male to female ratio in this study is (1.12:1) and this is in agreement with a study done by Ezeukwu AO. where the ratio was $(1.13: 1)^{(16)}$ but it is lower than another study done by Odyedeji $\mathrm{AO}$ et al where the ratio was $(1.7: 1)^{(13)}$.
The majority of the patients $94.45 \%$ had sustained their nerve injury by nurses while in a similar study $51.1 \%$ of the patients had sustained their nerve injury by unqualified medical practitioners ${ }^{(16)}$. This is due to inadequate health care facilities and to security condition which prevent the patients in this study from reaching the health centers or hospitals specially during the night. The exact site of injection can not be identified in all patients this is in agreement with other study ${ }^{(14)}$.

Upper respiratory tract infections, common during cold winter season in our locality, were the main indication for intramuscular injections. Antibiotics were the common offending agents in this study, because of their wide use; while in a study done at Nigeria, malaria was the main indication which is endemic there ${ }^{(13)}$. Chloroquine, pyrazolone, and procaine penicillin were the main offending agents in study done by Fatunde $\mathrm{OJ}$ and Familusi $\mathrm{JB}^{(17)}$ and quinine dihydrochloride ${ }^{(14)}$.

The onset of the symptoms was immediate in 94.44\% which is in agreement with another study done by Maqbool W, et al where the onset was immediate in $90.9 \%$ of the patients $^{(18)}$.

All the cases presented with unilateral lower limb involvement, the left lower limb affected in $63.88 \%$. This is in agreement with another study $^{(13)}$, while Ezeukwu AO. found that the right lower limb was more affected (in $52.1 \%$ of the patients) ${ }^{(16)}$. The male had higher percentage for either side to be affected and similar to other studies ${ }^{(13,16)}$. Ndiaye, et al performed sciatic nerve gluteal dissection on 10 fresh adult African cadavers, on both sides. The nerve pathway was 19 times out of 20 in the subpiriformis canal. In all cases the pathway was identical with an oblique and vertical portion running down through the ischio-trochanteric channel. The cutaneous projection of the sciatic nerve was distant from the upper lateral quadrant of the buttock ${ }^{(10)}$, (Fig. 2). 


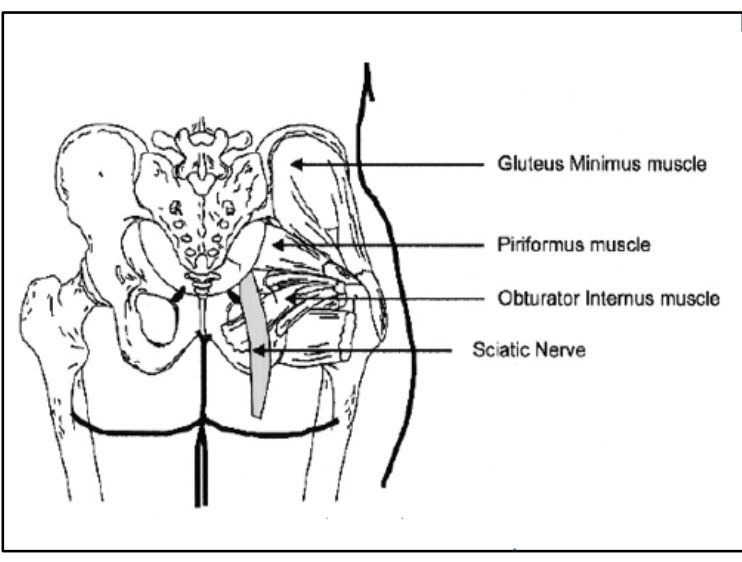

Figure (2): Anatomy of the sciatic nerve in the gluteal region.

The chief complaint at presentation are foot drop in $52.33 \%$ followed by leg and foot weakness in $30.55 \%$, pain and numbness in 8.3\% while in another study done in India the weakness of the foot and leg in 55.7\%; foot drop in $33.9 \%$ and pain and numbness in $18.8 \%$ of the patients ${ }^{(18)}$. Equinovarus deformity in $5.55 \%$ while in other study was $8 \%{ }^{(14)}$ and fibrotic scare in gluteal region in $2.7 \%$ which is similar to that noticed by Singh Khaimarj $^{(19)}$. The loss of sensory nerve action potential of sural nerve and a great vulnerability of the common peroneal nerve to injury by injection as well as by other mechanism has been noticed previously and the prognosis is good in patient with sensory nerve conduction abnormalities alone in the first electrophysiological study after the injection $^{(7,10,12)}$.

In this study $8.33 \%$ of the patients have decreased sensory nerve action potential of the sural nerve alone and they completely recovered. Twelve patients (33.33\%) had isolated involvement of the common peroneal nerve, 7 patients (19.44\%) had involvement of the posterior tibial nerve, and 14 patients (38.88\%) had involvement of both common peroneal and posterior tibial nerves equally while Maqbool W, et. al found that $1.9 \%$ of the patient had decrease amplitude of SNAP in sural nerve, $47.1 \%$ had isolated or predominant involvement of the common peroneal nerve, $17.9 \%$ had predominant involvement of the posterior tibial nerve and $26.4 \%$ of the patients had equal involvement of the common peroneal and posterior tibial nerves ${ }^{(18)}$.

Treatment of sciatic nerve injury following intramuscular injection is not specific although it is important to maintain joint movement and avoid damage to anaesthetic skin, ankle brace with vitamins may be helpful and there is no real evidence that exploration of the sciatic nerve with or without excision of the damaged portion and grafting is of any use but tendon transfers should be considered when there is permanent residual paralysis 15 months after the onset of the injury ${ }^{(4,10)}$.

The outcome of conservative treatment in this study was $29.6 \%$ of the patients completely recovered while $70.4 \%$ showed partial or no recovery this is in agreement with the results of three studies which showed partial or no recovery in $64 \%, 72 \%$ and $82 \%$ of the cases respectively ${ }^{(4,10,18)}$.

During follow up $9.6 \%$ of the patients develop wasting of leg and ulceration in the toes, while in other two studies 14 and $32 \%$ of the patients respectively had wasting of the leg and ulceration of the toes ${ }^{(14,18)}$ this may by due to a good care and physiotherapy of the affected limb of patients in this study.

\section{Conclusion}

- Children are at higher risk of injury than adults.

- Sciatic nerve injury presents most commonly as foot drop.

- In order to reduce for frequency of this handicapping condition, injection should be prescribed only when mandatory and administered by well qualified and competent personnel.

- The outcome of conservative treatment was poor.

\section{Referenses}

1. Simonsen L, Kane A, Lioyd J, Zaffran M, Kane M. Unsafe injection in the developing world and transmission of blood borne pathogens: Bull World Health Organ 1999; 77: 789-800.

2. Plewnia C, Wallace C, Zochodone D. Traumatic sciatic neuropathy: A novel cause, local experience and a review of the literature. J Trauma 1999; 45: 986-91. 
3. Ahuja B, Dhamija K. Sciatic Neuropathy. Ind pediatrics 1984; 21:797-801.

4. Kline DG, Kim D, Midha R, Harsh C, Tiel R. Management and results of sciatic nerve injuries: A 24-years experience. J Neurosurgery 1998; 89: 13-23.

5. Sharma S, Kale R. Post injection Paralysis in Chhatisgraph region. Ind pediatrics 2003; 40:508-1.

6. Kotwal A, Priya R, Thakur R, Gupta V, Kotwal J, Seth $\mathrm{T}$. Injection Practices in Metropolis of North India. Perceptions, determinants and issues of safety. Indian J Med Sci 2004; 58: 334-344.

7. Raglow GJ, Luby SP, Nabi N. Therapeutic injection in Pakistan from the patients perspective. Trop Med Int Health 2001; 6: 69-75.

8. Gentili F, Hudson A.R, Hunter D. Clinical and experimental aspects of injection injuries of peripheral nerves. Canadian Journal of Neurosurgical Sciences, 1980; 7 (2): 143-151.

9. Villarejo FJ, Pascual A M. Injection injury of the sciatic nerve 370 cases. Childs Nerve Syst 1993; 9: 229-32.

10. Ndiaye A, Sakho Y, Fall F, Dia A, and Sow $M$ L. Sciatic nerve in gleuteal portion: Application of sciatic nerve post injection lesion. Morphologies 2004; 88(282): 135138.

11. Halsey NA. Commentary: poliomyelitis and unnecessary injections. International Journal of Epidemlogy 2003; 32: 278-9.

12. Eric CY, Olney RK, So $Y$ T. Sciatic neuropathy: Clinical and Prognostic Features in 73 patients. Neurology 1994; 44: 1669-74.
13. Odyedeji OA, Elemile PO. Adebami OJ, Ojunlusi JD, Oyedeji GA, Oluwafemi S. Injection induced sciatic nerve injury among children seen at a Nijerian physiotgerapy Unit. The Internet journal of Third World Medicine 2006; 3(2).

14. Naddumba EK, Ndoboli P. Sciatic nerve palsy associated with intramuscular quinine injection in children. East and Central African Journal of Surgery 1999;2: 17-20.

15. Ahuja B. Post injection nerve injury. Indian pediatrics 2003; 21: 797-801.

16. Ezeukwu AO. Injection- induced sciatic nerve injury among children managed in Nigeria. Physiotherapy child: a five year review. Journal of Medicine and Rehablitation 2007; 1: 22-24.

17. Fatunde OJ, Familusi JB. Injection induced sciatic nerve injury in Nigerian children. Central African Journal of Medicine 2001; 47:35-8.

18. Maqbool W, Saleem S, Asrar A. Clinical, electrophysiological and prognostic study of post injection sciatic nerve injury: An avoidable cause of loss of limb in the peripheral medical service. Annals of Indian Academy of Neurology 2009; 12: 116-119.

19. Singh K. Sciatic nerve injury following intramuscular injection: a case report and review of the literature. Journal of Neuroscience Nursing 2006; 38 (4): 23840. 